Gregory Richards and Medhat Shehata (2020) "Effects of Curing Method on Properties and Salt-Scaling Resistance of Concrete under Lab Testing". Journal of Materials in Civil Engineering, ASCE, 32(8): 04020222 


\title{
Effects of Curing Method on Properties and Salt Scaling Resistance of Concrete under Lab Testing
}

\author{
Greg Richards, M.ASc. \\ Department of Civil Engineering, Ryerson University, 350 Victorial Street, Toronto, ON, \\ Canada M5B 2K3 \\ E-mail address: gregory.richards@ryerson.ca
}

\author{
Medhat H. Shehata, Ph.D., P.Eng.* \\ Department of Civil Engineering, Ryerson University, 350 Victorial Street, Toronto, ON, \\ Canada M5B 2K3 \\ E-mail address: mshehata@ryerson.ca \\ * Corresponding author. Tel.: 14169795000 ext 6457; fax: +1 4169795122
}

\begin{abstract}
This paper presents a study into the effect of curing on the salt scaling resistance of concrete containing Supplementary Cementitious Materials (SCMs) under lab conditions. Two curing methods were examined: moist curing and wrapping in a tight plastic sheet. Wrapping concrete slabs in plastic were adopted to represent curing methods that do not supply the concrete with additional water. The two curing methods produced different scaling results; however, the outcomes did not change in terms of meeting or failing the acceptance limit. Curing in plastic wraps produced a higher carbonation depth prior to exposing the sample to the salt solution. This could have contributed, partly, to the higher scaling obtained in wrapped samples, other than the sample with $40 \%$ high-calcium fly ash. For this sample, there is evidence that curing using plastic wraps maintained high alkali concentration in the surface concrete, which could have enhanced the pozzolanic activity of the fly ash at the surface.
\end{abstract}

\section{Introduction}

Concrete durability continues to be an important area of research because of the extensive use of concrete as a construction material. The durability of concrete is dependent on the 
environmental conditions in which it exists. The mechanisms of deterioration can be both physical and chemical. The process of salt scaling, marked by the progressive removal of small chips and flakes from a concrete surface, takes place during cycles of freezing and thawing in the presence of a saline solution. There is no single theory that is universally held to be the mechanism of this form of deterioration. Many theories, including glue-spall, hydraulic pressure and crystallization pressure, thermal shock, precipitation and growth of salts, and osmotic pressure, have all been proposed as possible mechanisms of salt scaling but none meet all of the necessary criteria to be solely responsible for the deterioration (Valenza II \& Scherer, 2007b). It seems that it is more likely some combination of the aforementioned mechanisms that lead to salt scaling.

Supplementary cementitious materials (SCMs) are and will continue to be an important part of concrete production and use. As it pertains to salt scaling, the type and quantity of SCMs play a major role in how well a concrete resists scaling. It has been shown that the incorporation of relatively high replacement levels of fly ash and slag in a concrete mixture reduces its resistance to salt scaling when tested under lab conditions (Chidiac \& Panesar, 2008; Marchand, Maltais, Machabée, Talbot, \& Pigeon, 1997; Pigeon, Talbot, Marchand, \& Hornain, 1996; Talbot, Pigeon, \& Marchand, 2000). Afrani and Rogers (1993) postulated that increased bleeding and reduced maturity in slag concretes may be the reason for the reduced salt scaling resistance. Surface properties such as sorptivity have indicated that higher rates, associated with increasing SCM replacements, could be one of the reasons for higher rates of scaling damage (Gagne, Houehanou, Jolin, \& Escaffit, 2011). It should be noted that the sorptivity test used by Gagne et al. (2011) was carried out with water placed on top of the sample to mimic a salt scaling test and following conditioning methods different than that in ASTM C1585(ASTM, 2013). Extended curing - 28 days instead of 14 days - was found to 
enhance the scaling resistance of concrete with SCMs (Gange et al. 2011). The slower reaction of SCMs, comparted to that of portland cement, requires longer curing time for concrete to mature which enhances the resistance to salt scaling. Recognizing this finding, the Canadian Standard Association test method for salt scaling (CSA A23.2-19 22C) requires concrete containing SCMs to be cured in a moist environment for 28 days rather than 14 days in case of concrete without SCMs.

Because salt scaling occurs in the surface of the concrete, it follows that the properties of the surface layer of concrete play a more important role in resisting salt scaling over those properties of deeper layers. Thus, the finishing and curing of a concrete specimen is of paramount importance in providing the surface of that specimen with the necessary hydration, microstructure, and stability to ensure adequate durability and resistance to salt scaling. In this research, deterioration due to salt scaling of concrete containing (SCMs) was evaluated under different lab curing conditions: water curing and wrapped curing. Under the latter method of curing, samples were cured in plastic wrapping as an alternative to curing compound under laboratory conditions. Principally, this methodology was meant to maintain only the water within the concrete as a means for curing; similar to that of curing compound use. Some suggest, however, that when curing compound is removed prior to testing, a portion of the weak surface layer most susceptible to damage is simultaneously removed leading to improved resistance results and thus is not indicative of field applications where the compound is not removed from in-service usage (Bilodeau, Carette, \& Malhotra, 1991; Bilodeau \& Malhotra, 1997; Valenza II \& Scherer, 2007a). Boyd and Hooton reported enhanced performance of concrete with SCM's under field conditions when cured by curing compound (Boyd and Hooton, 2007). Conversely, it is suggested that when curing compound is left on the surface during testing, the scaling is only delayed and can actually exacerbate scaling as 
larger chunks of material, bound by the compound itself, are removed (Valenza II \& Scherer, 2007a). Ahani and Nokken tested slabs cured by curing compound - without brushing off the curing compound prior to testing - and others that were moist cured for 3 days and 14 days (Ahani and Nokken, 2012). Their results showed that for concrete with low-calcium fly ash or slag, the use of curing compound produced the least resistance to salt scaling. For samples without SCMs, curing compound produced the best results. The use of the plastic wrapping in the current research serves to eliminate the influence of curing compound during testing whilst still providing the same curing conditions present when a perfectly applied curing compound is provided. Furthermore, extended moist curing was found to have no clear trend by Bilodeau, Zhang, Malhotra, and Golden (1998), while Gagne et al. (2011) found a systematic trend in improved salt scaling resistance associated with extended curing duration from 14 days to 28 days. As noted above, Afrani and Rogers (1993) postulated that extended curing of concrete containing SCMs, specifically slag, would likely result in improved resistance to salt scaling with improved surface properties.

In terms of lab testing, Bouzoubaâ et al. reported that the ASTM C 672-03 test procedures which is similar to the method adopted in this paper except for the type and concentration of salt - is aggressive and may not represent the performance of concrete with SCMs under field conditions (Bouzoubaâ et al., 2008, 2011). Bouzoubaâ et al. also reported that the salt scaling test adopted by the province of Quebec, Canada (BNQ 2002) is more representative of field conditions. The CSA test method CSA A23.2:19, 22C adopted some conditions from the BNQ method, including using a geotextile material under the slab to mimic granular base and reduce bleeding in lab-prepared samples. 


\section{Experimental Program}

\subsection{Materials}

\subsubsection{Cementing Materials}

Three cementing materials were used in this project: a general use (GU) portland cement, high calcium fly ash (HCFA) and slag. The chemical analyses are presented in Table 1.

Table1. Chemical analysis of the cementing materials (\%)

\begin{tabular}{ccccccccccc}
\hline Mat. ID & $\mathrm{SiO}_{2}$ & $\mathrm{Al}_{2} \mathrm{O}_{3}$ & $\mathrm{Fe}_{2} \mathrm{O}_{3}$ & $\mathrm{CaO}$ & $\mathrm{MgO}$ & $\mathrm{SO}_{3}$ & $\mathrm{~K}_{2} \mathrm{O}$ & $\mathrm{Na}_{2} \mathrm{O}$ & $\mathrm{Na}_{2} \mathrm{O}_{\mathrm{e}}$ & Loss on ignition \\
\hline PC & 19.54 & 5.21 & 2.16 & 62.39 & 2.39 & 4.03 & - & - & 0.99 & 2.36 \\
HCFA & 37.31 & 20.76 & 5.19 & 24.29 & 4.05 & 1.83 & 1.50 & 0.57 & 1.90 & 0.39 \\
SLAG & 36.95 & 8.18 & 0.51 & 38.51 & 10.47 & 2.70 & 0.52 & 0.33 & 0.67 & 3.01 \\
\hline
\end{tabular}

\subsubsection{Chemical Admixtures and Solutions}

An alkaline solution of fatty acid salts and sulfonates-based air-entraining admixture (AEA) in compliance with ASTM C260 was used in all mixtures (ASTM, 2016). A polycarboxylatebased high-range water reducer, or superplasticizer (SP), in compliance with ASTM C494 Type F was used in all mixes except the 40HCFA mix where no SP was needed (ASTM, 2016). A $1 \%$ phenolphthalein volumetric indicator solution was used for the determination of carbonation depth in concrete slab samples. The visual transition interval is $\mathrm{pH} 8.2$ (colourless) to $\mathrm{pH} 10.0$ (Red). The de-icing salt solution was a 3\% sodium chloride $(\mathrm{NaCl})$ solution. Slab surfaces were covered with enough $\mathrm{NaCl}$ solution to provide a $6 \mathrm{~mm}$ deep pool of solution on the surface of the slab and exposed to continuous freeze-thaw cycling.

\subsubsection{Aggregates}

The coarse aggregate used is a quarried Dolostone from Hamilton, Ontario. The fine aggregate is natural sand from Caledon, Ontario. The material properties are listed in Table 2. The average bulk densities of the coarse and fine aggregate were determined using Canadian 
Standard Association (CSA) test methods CSA A23.2-12A and CSA A23.2-6A, respectively, while the dry-rodded density was determined using CSA A23.2-10A (CSA, 2014).

Table 2. Properties of coarse aggregate and fine aggregate

\begin{tabular}{cccc}
\hline \multirow{2}{*}{ Property } & \multirow{2}{*}{ Unit } & Coarse aggregate & Fine aggregate \\
\cline { 3 - 4 } & & Dolostone & Natural Sand \\
\hline Absorption & $\%$ & 0.87 & 1.05 \\
Bulk Relative Density & \multirow{2}{*}{$\mathrm{kg} / \mathrm{m}^{3}$} & 2,729 & 2,637 \\
Dry Rodded Density & & 1,648 & - \\
\hline
\end{tabular}

\subsubsection{Mix Proportions}

Table 3 lists the proportions of the four mixtures used in this investigation. In addition to a control mix containing no SCM, three additional mixtures were used with 40\% HCFA, 40\% Slag and a third mix with a ternary blend of $20 \%$ HCFA and $20 \%$ Slag.

Table 3. Proportions of the investigated concrete mixtures

\begin{tabular}{cccccc}
\hline & \multicolumn{5}{c}{ Mix ID } \\
\cline { 2 - 6 } Property & Unit. & CON & 40HCFA & 40SLAG & $20 / 20$ \\
\hline w/c & - & 0.45 & 0.43 & 0.45 & 0.45 \\
Coarse Aggregate & $\left(\mathrm{kg} / \mathrm{m}^{3}\right)$ & $1,084.7$ & $1,084.7$ & $1,084.7$ & $1,084.7$ \\
Fine Aggregate & & 784.7 & 742.9 & 738.6 & 731.5 \\
Effective Water & & 157.5 & 150.5 & 157.5 & 157.5 \\
PC & & 350 & 210 & 210 & 210 \\
HCFA & & - & 140 & - & 70 \\
SLAG & & - & - & 140 & 70 \\
AEA & $\left(\mathrm{mL} / \mathrm{m}^{3}\right)$ & 70 & 80 & 70 & 70 \\
SP & & 120 & - & 120 & 40 \\
\hline
\end{tabular}

\subsection{Procedure}

\subsubsection{Casting and Curing}

Ten concrete slabs of dimension 300 X 300 X 75 mm were cast using plywood moulds for salt scaling testing according to Ministry of Transportation Ontario, test method, LS-412 for 
each mix design (MTO, 1997). In this method, the concrete slabs undergo 50 freeze-thaw cycles while exposed to a solution with a $3 \%$ sodium chloride $(\mathrm{NaCl})$ solution. At the end of each five-cycle interval, the slab surface is flushed, and the scaled particles are collected and weighed. The failure criterion of LS-412 is met when the quantity of scaled particles is equal to or greater than $0.8 \mathrm{~kg} / \mathrm{m}^{2}$ with respect to the surface area of a specimen. Additionally, twelve preformed polyurethane cylinder moulds of diameter $100 \mathrm{~mm}$ and height $200 \mathrm{~mm}$ were cast concurrently with each mix to be used for compressive strength testing. During each cast, bleeding, slump, and air content tests were carried out according to ASTM C232, ASTM C143, and ASTM C231, respectively (ASTM, 2014a, 2014b, 2015).

Two curing regimes were used for the experimental program: (a) moist curing, where the samples were cured for 2 weeks in a curing room at $23{ }^{\circ} \mathrm{C}$ and $100 \% \mathrm{RH}$, and (b) wrapped curing, where the samples were sealed in polyethylene wrapping and cured for two weeks at ambient temperature $\left(21\right.$ to $23^{\circ} \mathrm{C}$ ). This is to represent curing with a perfectly applied curing compound. A weatherproof data logger with a built-in temperature and relative humidity sensor - Model HOBO Pro V2 - was placed beside the slabs and wrapped in a plastic sheet or kept in the curing room depending on the adopted curing methods. The sensors have weatherproof housing for use in an outdoor or condensing environment. The Specimens for all testing programs were divided and cured according to the two curing regimes. After the two weeks of moist or wrapped curing, samples were stored for an additional two weeks in a drying room at a temperature of $23 \pm 2{ }^{\circ} \mathrm{C}$ and relative humidity $(\mathrm{RH})$ of $50 \pm 5 \%$. Actual relative humidity and temperature measured during the storage of the samples are presented in the Results section. 


\subsubsection{Testing}

The following hardened properties of the concrete were determined: 1) Salt Scaling, 2) compressive strength, 3) alkali cations $\left(\mathrm{Na}^{+}\right.$and $\left.\mathrm{K}^{+}\right)$concentrations at concrete surface, 4) depth of carbonation, 5) sorptivity, and 6) surface resistivity.

\section{Salt Scaling}

Salt scaling tests were carried out on slabs that were either moist cured or cured by wrapping according to MTO LS-412 (MTO, 1997). The standard called for curing the samples for 14 days followed by drying the samples for another 14 days at a temperature of $23 \pm 2{ }^{\circ} \mathrm{C}$ and relative humidity $(\mathrm{RH})$ of $50 \pm 5 \%$. Although test method LS-412 is somewhat similar to ASTM C672, the are main differences that are summarized here. The finishing procedure differs in both the timing and process of final finishing. LS-412 calls for final finishing to take place immediately after the screeding of excess material using only two perpendicular strokes with a wood trowel as opposed to the three sawing motion strokes after the cessation of bleeding in ASTM C672. ASTM C672 calls for a 4\% calcium chloride solution which differs from the $3 \%$ sodium chloride salt solution required by MTO LS-412. Additionally, during specimen flushing, MTO LS-412 requires that the same $3 \% \mathrm{NaCl}$ solution is used to clear surface of scaled particles and maintain the required $6 \mathrm{~mm}$ solution level on the slab surface during freeze-thaw cycling as opposed to the use of water in ASTM C672. Finally, the reporting of results for MTO LS-412 uses a quantitative approach (mass loss) versus the qualitative approach adopted in ASTM C672. MTO LS-412 requires that after each 5 cycles all salt solution and flaked off particles are collected, strained through a filter, and dried to a constant mass at $105^{\circ} \mathrm{C}$ to attain the mass of scaled particles. The cumulative mass of residue is attained for a minimum of 50 cycles which represents the mass loss of a specimen and expressed in kilograms per square meter of exposed slab area. 


\section{Compressive Strength}

Compressive strength test was carried out using cylinders of $100-\mathrm{mm}$ diameter by $200-\mathrm{mm}$ height following CSA A23.2-9C. The samples were cast from the same mixtures used in the salt scaling test but cured using the standard curing method in a moist room until the time of testing. Two cylinders were crushed to determine the compressive strength at 32 and 56 days (28 days' strength could not be done due to maintenance of the crushing machine).

\section{Alkali Cation Concentrations at Concrete Surface}

The concentration of alkali cations at the surface was tested by soaking drilled powder samples - collected from the top $2 \mathrm{~mm}$ - in distilled deionized water (DDW) - at a temperature between 21 to $23{ }^{\circ} \mathrm{C}$ - and measure the sodium and potassium concentration after 28 days of soaking at room temperature. The samples were collected from the surface of the slabs, as seen in Fig. 1 at the age of 28 days prior to starting the salt scaling test. The collected powder samples were soaked in DDW at a solid-to-water ratio of 1:10 using a dry sample mass of $1.5 \mathrm{~g}$. Three specimens from each sample were tested, and the average was reported.

\section{Depth of Carbonation}

For depth of carbonation, one additional slab was cast for each mix and curing regime. The additional slabs were cured using either the wrapped or moist curing. At the age of 28 days (14 days of curing followed by 14 days of drying, the slabs were split down the centre to expose the profile of the slab from top to bottom. The exposed surface was then immediately sprayed with a $1 \%$ Phenolphthalein solution to determine the transition depth between carbonated and uncarbonated regions of the slab. 

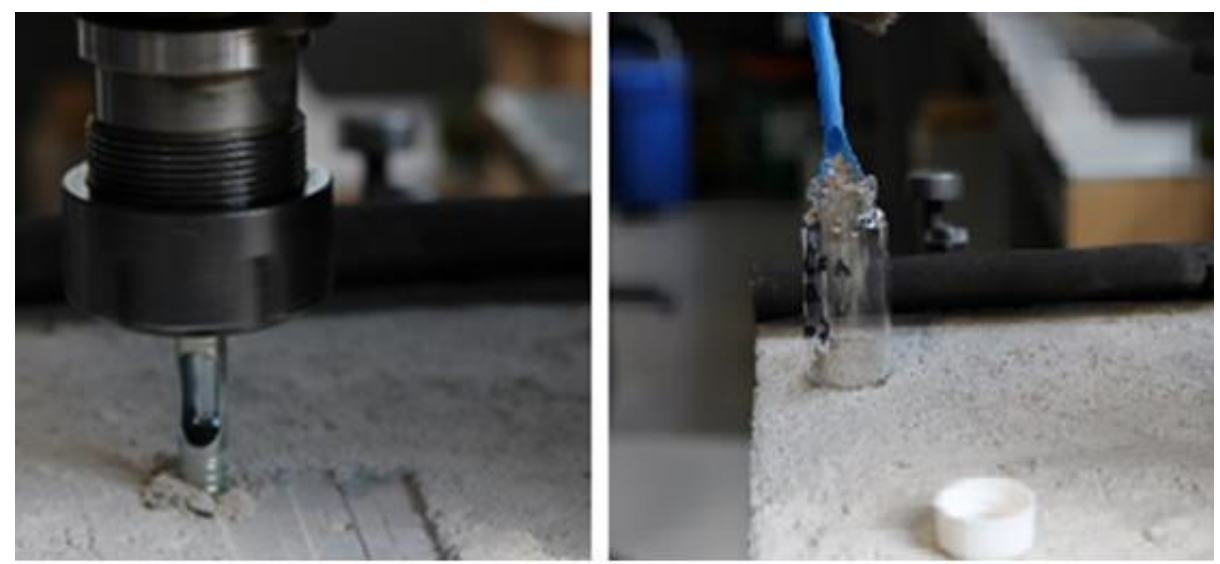

Fig. 1. Left: diamond bit grinding slab surface, and right: collection of concrete powder

\section{Sorptivity}

Three sorptivity samples were cored from a slab and vacuum saturated according to ASTM C1202, 2012 as required by the sorptivity test: ASTM C1585, 2013 for cored samples. After the vacuum saturation, the samples were conditioned as per ASTM C1585 (sorptivity test) to achieve a relative humidity within the samples similar to that found near the surface of some concrete structures, as stated in ASTM C1585, 2013. Multiple sorptivity samples were tested simultaneously using the apparatus shown in Fig. 2. The main objective of this test setup is to maintain the water at the desired level by providing additional water to compensate for evaporation and draining water in excess of the required water level.

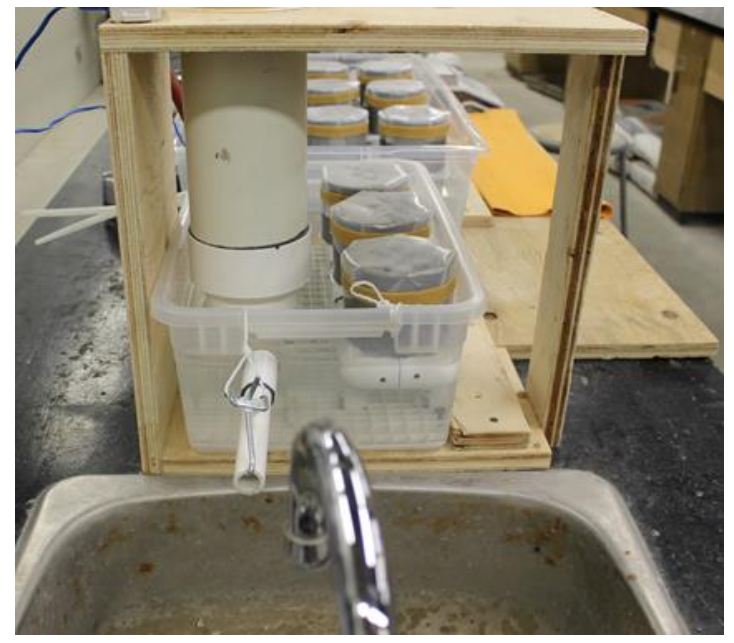

Fig. 2. Testing apparatus used in the determination of sorptivity 


\section{Resistance of Surface Concrete}

To determine the surface electrical resistance of the slabs used in the salt scaling experiments, the slab surfaces were tested using a 4-point Wenner probe immediately prior to exposing the slabs to the salt solution in the salt scaling test. Measurements were taken at four positions on the exposure face of the concrete slabs as shown in Fig. 3.

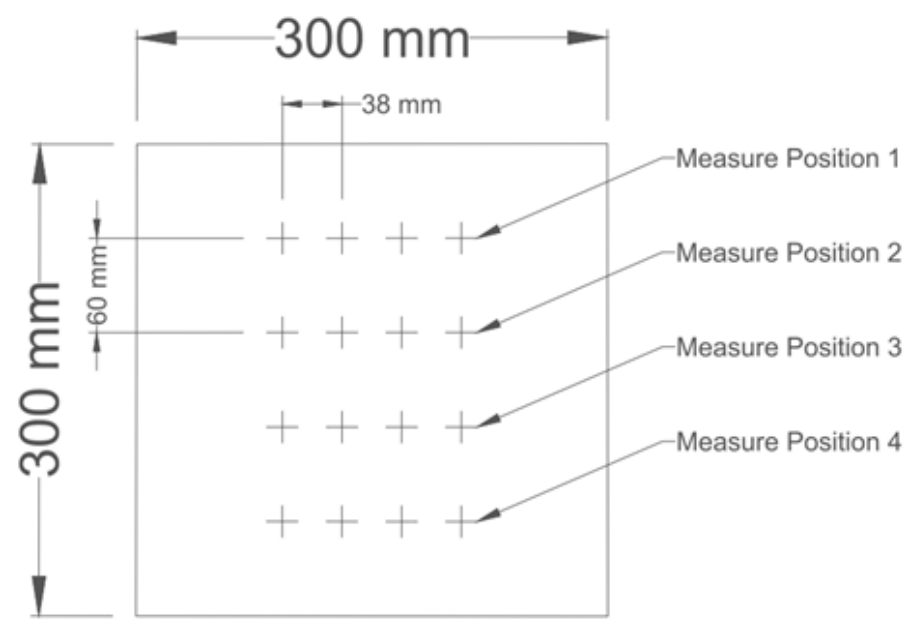

Fig. 3. Measurement positions for 4-point Wenner probe on the surface of concrete slabs

\section{Results and Analysis}

\subsection{Fresh Properties and Relative Humidity During Curing}

Table 4 lists the fresh properties of each concrete mix. The four mixtures achieved similar slump and air content values; however, there were some differences in the bleeding of the four mixtures.

Table 4. Fresh concrete properties

\begin{tabular}{ccccc}
\hline & \multicolumn{4}{c}{ Mix ID } \\
\cline { 2 - 5 } Property & CON & 40HCFA & 40SLAG & $\mathbf{2 0 / 2 0}$ \\
\hline Slump (mm) & 105 & 105 & 100 & 115 \\
Air Content (\%) & 5.5 & 5.0 & 5.9 & 5.0 \\
Bleeding (\%) & 0.91 & 0.54 & 2.11 & 1.64 \\
\hline
\end{tabular}


Humidity sensors were placed inside of the wrapped specimens and in the moist room during the curing period. As shown in Fig. 4, relative humidity (RH) was 100\% throughout the curing period for the 40SLAG and 20/20 samples. For the control and the 40HCFA-samples, there were slight variations at a limited time during the curing period with mean $\mathrm{RH}$ values of $96.7 \%$ and $99.4 \%$, respectively. The measurements of humidity in the wrapped samples were carried out to make sure that the wrapping was tight. The moist room consistently exhibited $100 \%$ $\mathrm{RH}$ for the duration of the curing period. While measuring $\mathrm{RH}$ at values close to $100 \%$ might not be accurate, the results showed that the humidity was more or less close to $100 \%$ during curing. RH sensors were also placed in the shrinkage room where the RH and temperature are controlled (the targets are $21-23{ }^{\circ} \mathrm{C}$ and $45-55 \mathrm{RH}$ ). This room had a consistent humidity reading of near $60 \% \mathrm{RH}$ which was above the $45-55 \%$ RH specified in MTO LS-412 (MTO, 1997). The samples, however, were all dried in the same shrinkage room at the same condition.
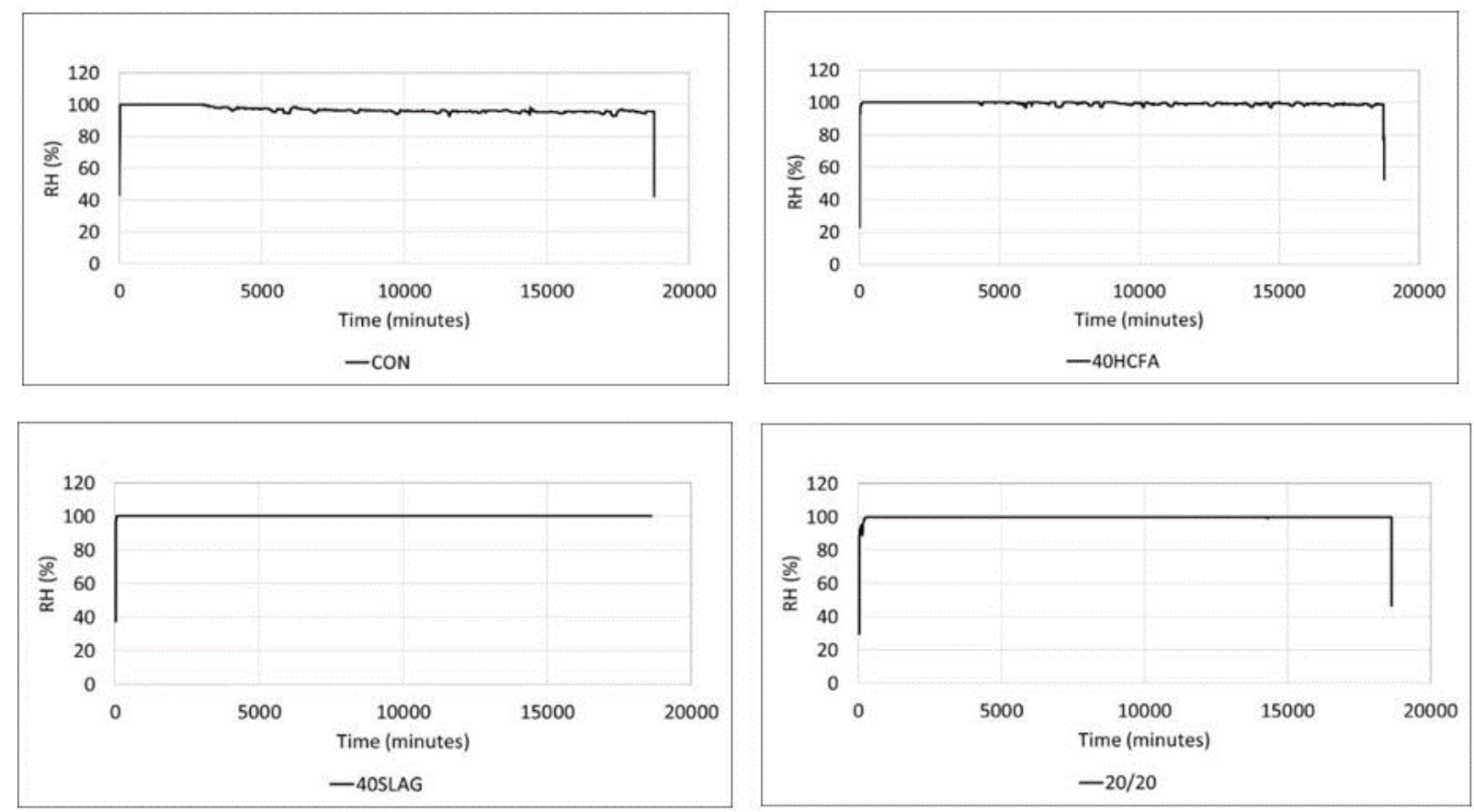

Fig. 4. Relative humidity in the wrapped slabs during the curing period. 


\subsection{Compressive Strength}

The compressive strength of samples from all mixtures is shown in Fig. 5 and Fig. 6 at 32 days and 56 days, respectively. Salt scaling is controlled largely by the surface properties of the concrete; thus a relationship between compressive strength and scaling was not expected (Valenza II \& Scherer, 2006). In general, the curing method did not have much effect on the obtained compressive strength.

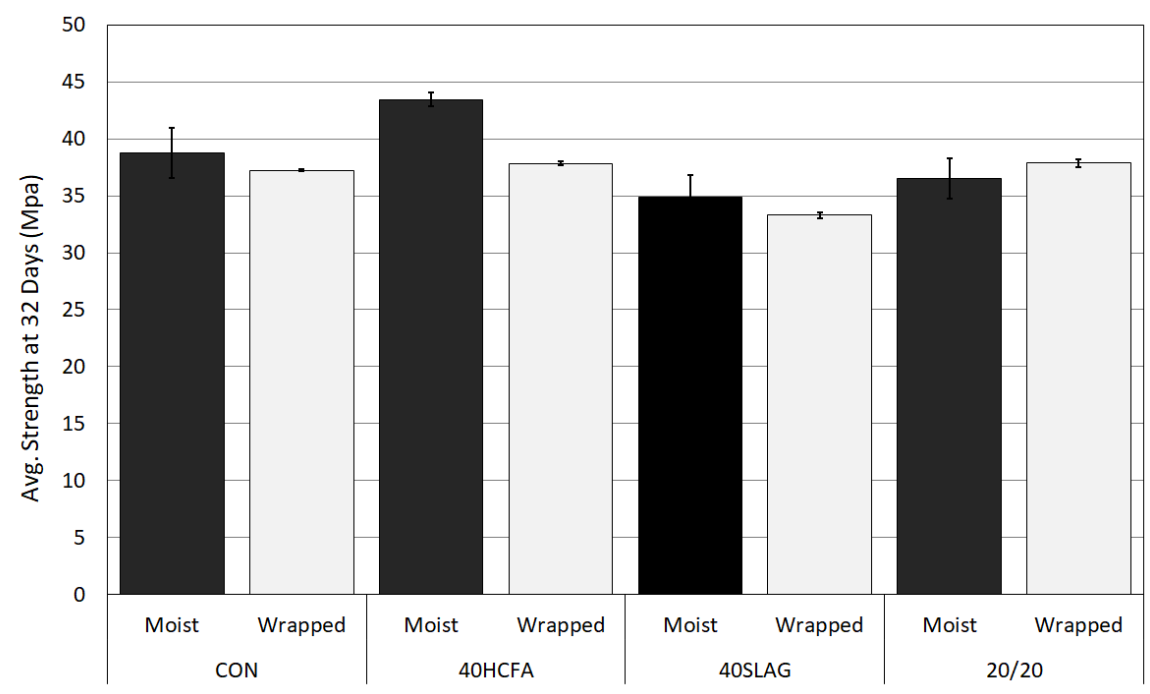

Fig. 5. Compressive strength under different curing conditions at 32 days.

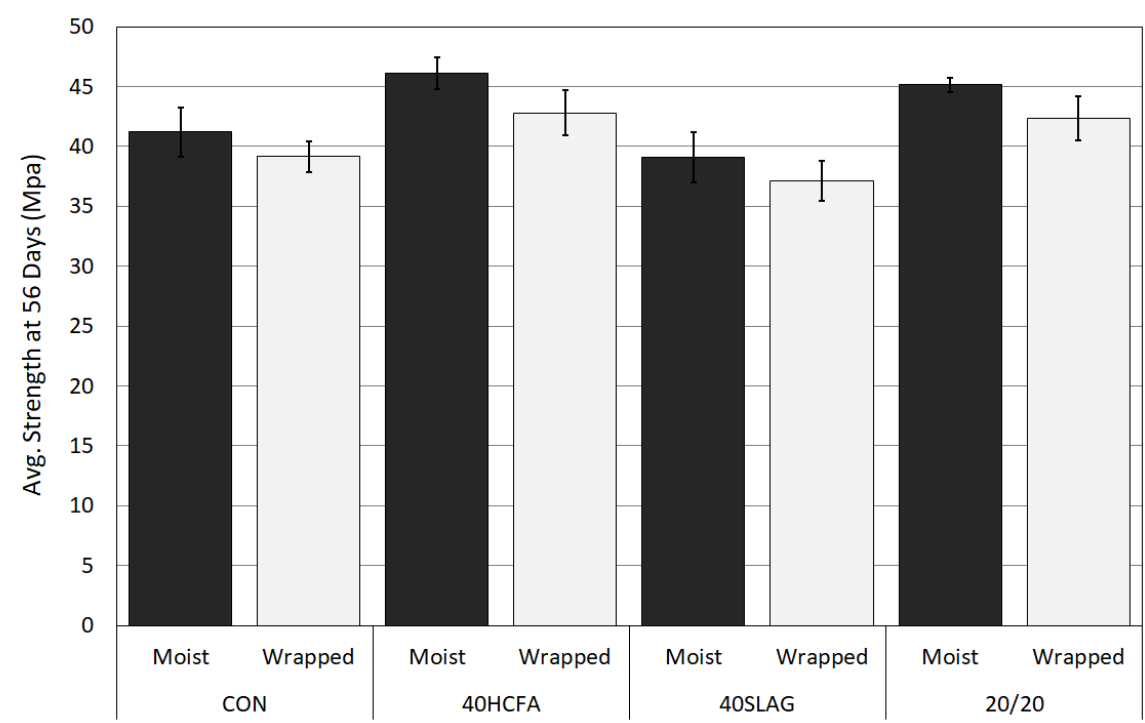

Fig. 6. Compressive strength under different curing conditions at 56 days. 


\subsection{Salt Scaling}

All samples that included SCMs failed the $0.80 \mathrm{~kg} / \mathrm{m}^{2}$ scaling mass loss after 50 cycles criterion specified by the Ontario Provincial Standard Specification OPSS 1002, for MTO LS412 (OPSS, 2013). Control samples showed high resistance to salt scaling. The results of salt scaling experiments can be found in Fig. 7, which shows the average mass loss with min./max. bars for the tested mixtures. It should be noted that the salt scaling was not related to the compressive strength reported in Fig. 5 and Fig.6, which highlights the surficial nature of salt scaling damage (Gagne et al., 2011; Valenza II \& Scherer, 2006).

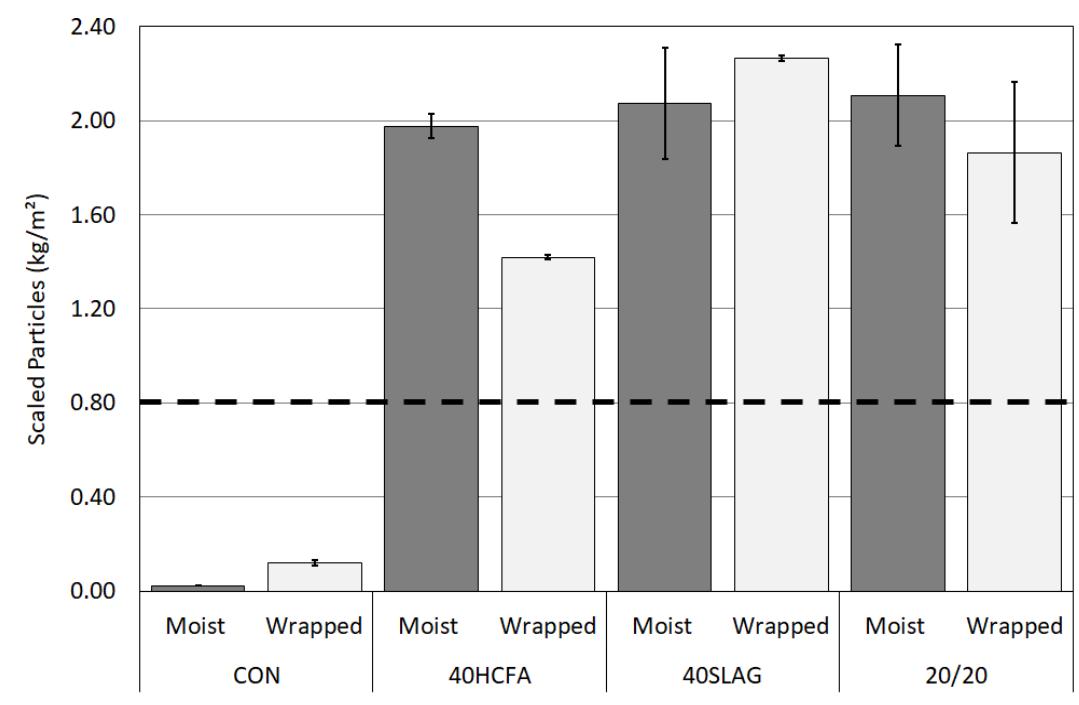

Fig.7. Mean scaling damage for all mixes and curing regimes after 50 freeze-thaw cycles according to MTO LS-412 (MTO, 1997).

\subsection{Level of Alkali Cations at Surface}

The mean values for the $\mathrm{N}^{+}$and $\mathrm{K}^{+}$released from the powder samples after 28 days of soaking in distilled water are shown in Fig. 8. For each mix and curing regime, three samples were derived from the same ground material, and three measurements were taken from each leaching sample.

The data shows the low variability and similarity of the alkali compositions of the ground material within a given sample. The control and the sample with $40 \%$ HCFA showed 
noticeable differences between alkalis released from the surface under different curing regimes, with the warped curing showing more available alkali cations. On the other hand, samples with slag and the ternary blend did not show significant differences between wrapped and moist-cured samples. While it was anticipated that moist-cured samples would lose more alkalis from their surface from leaching, this did not take place in samples with slag and slag/HCFA. The reason for this was not examined; however, the location of these slabs within the curing room may not have allowed significant leaching of surface alkalis. Alternatively, the latent hydraulic reaction of slag could have resulted in a higher early degree of hydration and refinement of pore structure - compared to samples with HCFA - leading to less alkali leaching from the surface of the samples under moist curing.

The CON mix showed the greatest difference in alkali contents between the wrapped and moist conditions. This was expected as samples without SCM may leach alkalis more readily during moist curing due to: (a) more alkalis are available in pores solution in samples without SCM as reported by Shehata, Thomas, and Bleszynski (1999), and (b) samples without SCM have coarser pore structures that allow for more leaching to occur.

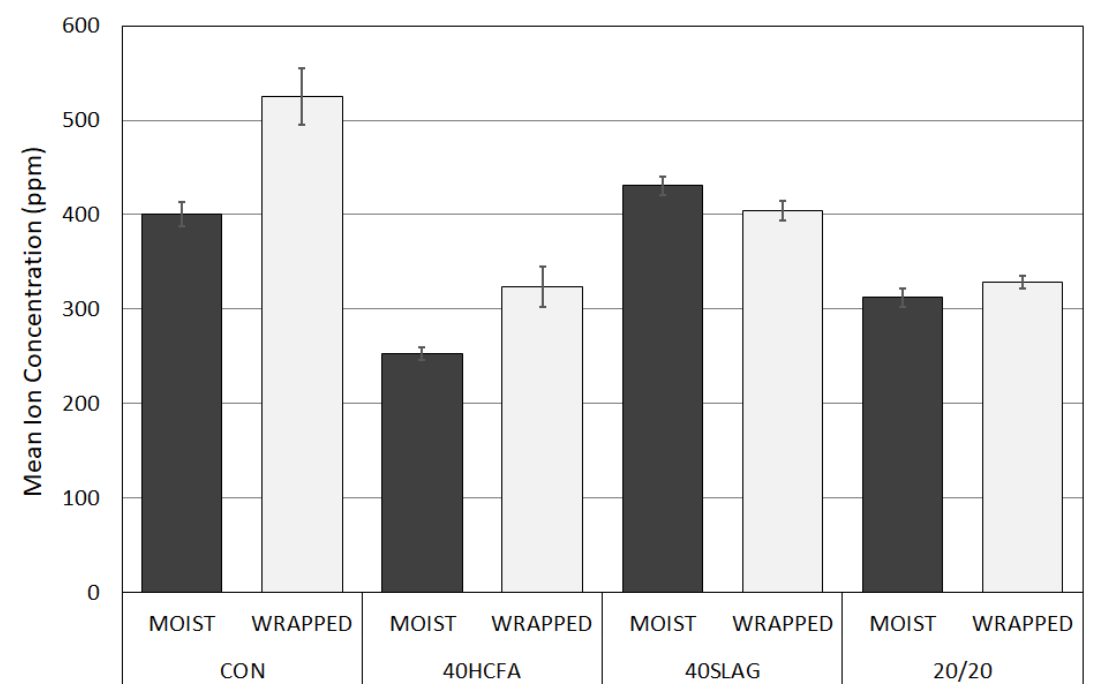

Fig. 8. Mean concentration of $\mathrm{Na}^{+}+\mathrm{K}^{+}$in the surface of the slabs under different curing conditions. 


\subsection{Depth of Carbonation}

The results of the mean depths of carbonation and the probability calculation (P-value) obtained from statistical hypothesis testing are presented in Table 5. The P-value is a statistical benchmark for the significance of the data. With a confidence interval of $95 \%$, a P-Value that is less than 0.05 (generated by regression analysis) means that the compared data are considered significantly different. A two-tail analysis is used in cases when the user has no expectation of a trend in either direction, i.e., which variable is expected to be higher or lower than the other. Samples with SCM showed greater depths of carbonation, likely due to reduced portlandite content leading to deeper carbonation (Papadakis, 2000; Neville, 2011). This is because concrete with SCM has less $\mathrm{Ca}(\mathrm{OH})_{2}$, which results in a higher carbonation rate or depth. In other words, if we assume that the same amount of carbonated $\mathrm{Ca}(\mathrm{OH})_{2}$ or $\mathrm{CaCO}_{3}$ exists in samples with and without SCM, this same amount of $\mathrm{CaCO}_{3}$ would occupy more depth in samples with SCM due to the lower availability of $\mathrm{Ca}(\mathrm{OH})_{2}$ within the matrix. This is assuming that all conditions are the same, including the ability of $\mathrm{CO}_{2}$ to penetrate the samples. A similar finding and explanation was provided by Papadakis, 2000. In addition, more carbonation of calcium silicate hydrate $(\mathrm{CSH})$ takes place in samples with less $\mathrm{Ca}(\mathrm{OH})_{2}$, such as those with SCM (Papadakis, 2000). All but the 20/20 mix were found to show statistically significantly different results with the wrapped samples showing a greater mean depth. It can be expected that the high moisture content in the water-cured samples may extend the time the samples take - while in the shrinkage room - to dry out to the RH level required to sustain carbonation which is $50-60 \%$ as reported by Galan, Andrade, and Castellote (2013). On the contrary, the wrapped cured samples, having less moisture content, would have reached such condition quicker, leading to increased carbonation for a given exposure time. Fig. 9 depicts the measured cross-section of the slab treated with $1 \%$ phenolphthalein solution. 
Table 5. Statistical evaluation of results from depth of carbonation (DOC) testing for concrete slabs tested at the age of 28 days (14 days of curing followed by 14 days of drying)

\begin{tabular}{|c|c|c|c|c|c|c|c|c|}
\hline \multirow{3}{*}{ Property } & \multicolumn{8}{|c|}{ Mix ID } \\
\hline & \multicolumn{2}{|c|}{ CON } & \multicolumn{2}{|c|}{ 40HCFA } & \multicolumn{2}{|c|}{ 40SLAG } & \multicolumn{2}{|r|}{$20 / 20$} \\
\hline & Moist & Wrapped & Moist & Wrapped & Moist & Wrapped & Moist & Wrapped \\
\hline $\begin{array}{l}\text { Mean depth of } \\
\text { carbonation (mm) }\end{array}$ & 1.08 & 1.49 & 1.32 & 1.78 & 1.48 & 2.31 & 1.74 & 2.28 \\
\hline Coefficient of variation & 0.11 & 0.21 & 0.13 & 0.14 & 0.09 & 0.24 & 0.41 & 0.18 \\
\hline P-value (two-tail) & \multicolumn{2}{|c|}{$1.13 \times 10^{-3}$} & \multicolumn{2}{|c|}{$1.41 \times 10^{-4}$} & \multicolumn{2}{|c|}{$2.38 \times 10^{-4}$} & \multicolumn{2}{|c|}{0.052} \\
\hline
\end{tabular}

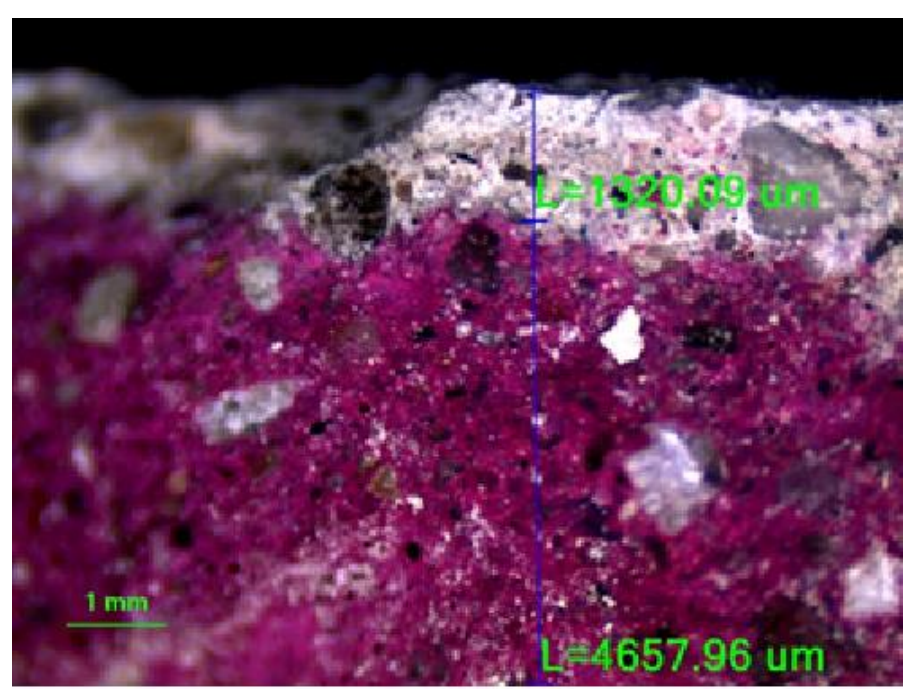

Fig. 9. Cross-section of slab treated with $1 \%$ Phenolphthalein solution and measured under a microscope - Sample \# 40HCFA moist-cured.

\subsection{Sorptivity}

The sorptivity results for each mix are presented in Table 6. In all samples except the 40HCFA, the initial and secondary sorptivity was greater in the wrapped condition. When considering these results, it is evident that the surface properties of the concrete are influenced by the inclusion of SCMs. The sorptivity rate is influenced by the properties of the concrete surface, particularly the characteristics of the capillary network (Gagne et al., 2011). The capillary network changes in relation to the degree of hydration and carbonation of the constituent materials of the mix (Mehta \& Monteiro, 2006; Ngala \& Page, 1997; Stark \& Ludwig, 1997). The sorptivity and carbonation followed a proportional trend as shown in Fig. 
10; samples with higher carbonation showed a high sorptivity rate. This is expected as high carbonation, especially when CSH is carbonated, leads to a more connected pore structure or higher permeability (Nagla and Page, 1997, Papadakis, 2000). It is clear from Fig. 10 that the wet cured samples had both lower carbonation depth and sorptivity.

Table 6. Initial and secondary sorptivity

\begin{tabular}{|c|c|c|c|c|c|c|c|c|}
\hline \multirow{3}{*}{$\begin{array}{l}\text { Sorptivity Rate } \\
\left(\times 10^{-3} \mathrm{~mm} / \sqrt{\mathrm{s}}\right)\end{array}$} & \multicolumn{8}{|c|}{ Mix ID } \\
\hline & \multicolumn{2}{|c|}{$\mathrm{CON}$} & \multicolumn{2}{|c|}{ 40HCFA } & \multicolumn{2}{|c|}{ 40SLAG } & \multicolumn{2}{|c|}{$20 / 20$} \\
\hline & Moist & Wrapped & Moist & Wrapped & Moist & Wrapped & Moist & Wrapped \\
\hline Initial & 1.34 & 1.64 & 0.64 & 0.57 & 0.73 & 1.15 & 0.65 & 1.00 \\
\hline $\mathrm{COV}$ & 0.079 & 0.041 & 0.131 & 0.098 & 0.045 & 0.171 & 0.166 & 0.075 \\
\hline $\begin{array}{l}\text { P-value } \\
\text { (two-tail) }\end{array}$ & \multicolumn{2}{|c|}{0.0007} & \multicolumn{2}{|c|}{0.3607} & \multicolumn{2}{|c|}{0.0229} & \multicolumn{2}{|c|}{0.0099} \\
\hline Secondary & 1.07 & 1.12 & 0.30 & 0.25 & 0.42 & 0.52 & 0.29 & 0.62 \\
\hline $\mathrm{COV}$ & 0.141 & 0.064 & 0.029 & 0.019 & 0.078 & 0.2399 & 0.058 & 0.088 \\
\hline $\begin{array}{l}\text { P-value } \\
\text { (two-tail) }\end{array}$ & \multicolumn{2}{|c|}{0.6415} & \multicolumn{2}{|c|}{0.0008} & \multicolumn{2}{|c|}{0.2335} & \multicolumn{2}{|c|}{0.0006} \\
\hline
\end{tabular}

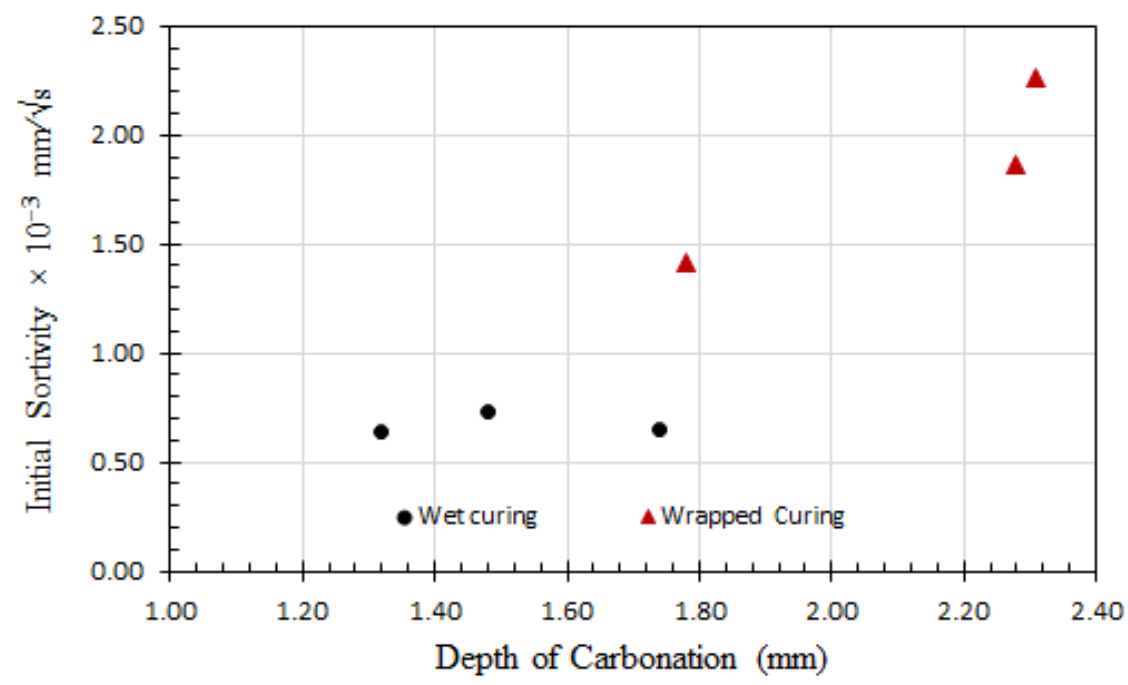

Fig. 101. Effect of depth of carbonation on sorptivity

For the 40HCFA and unlike all other samples, there was a small decrease in sorptivity for the wrapped sample as depicted in Table 6. Compared to all other mixes, the result for HCFA shows the only beneficial effect in reduced sorptivity for the wrapped condition. This is likely due to a possibly higher degree of pozzolanic reaction at the surface concrete of this sample as a result of the observed high level of alkalis. Fig. 8 shows that this mix had higher levels 
of $\mathrm{Na}^{+}+\mathrm{K}^{+}$in the wrapped sample than those in the moist-cured sample. It should be noted that the analysis was carried out after two weeks of curing -whether wrapped or moist cured - at $100 \% \mathrm{RH}$, a condition that does not sustain carbonation. Hence, the presence of high $\mathrm{Na}^{+}$ and $\mathrm{K}^{+}$ions in this case is an indication of high alkalinity. Hence, the surface concrete of the wrapped slab had two weeks of curing at $100 \% \mathrm{RH}$ and relatively high alkalinity conditions leading to better pozzolanic reaction of the HCFA. This is in line with Lawler (2007); Popovics (1992); and Shehata (2001), who all noted that it is the attack on the glass in fly ash by hydroxyl ions that provide the reaction necessary for fly ash pozzolanic activity. The enhanced pozzolanic reaction could be the reason for this sample to have lower sorptivity and higher scaling resistance, despite its relatively high carbonation depth. Perhaps similar reasons are partly behind the enhanced performance of field samples reported in the work of Boyd and Hooton, 2007.

The 40SLAG mix showed significantly lower sorptivity in the moist samples, which again likely denotes the influence of a higher degree of hydration of the slag under the moist condition. Slag exhibits latent hydraulic reaction as discussed by Thomas (2013) which is sustained under moist conditions. The results of the 20/20 mix indicate that the pozzolanic activity of the fly ash in this quantity was not high enough to have a significant difference between wrapped and wet curing. Moreover, this sample, as the sample with $40 \%$ Slag, did not show a significant difference in the alkali content at the surface; hence the degree of pozzolanic reaction is not expected to be different between the two curing methods.

The CON sample showed better sorptivity for moist-cured sample, likely due to enhanced hydraulic reaction. Although both warped and moist curing produce $100 \% \mathrm{RH}$, curing by water has shown here and in previous work by Siddiqui, Nyberg, Smith, Blackwell, and Riding (2013), that curing in the presence of excess water produces higher degrees of 
hydration compared to sealed samples in pastes made with portland cement. It is likely that the excess water maintains higher humidity within the pores of the sample compared to wrapping - despite the $100 \% \mathrm{RH}$ created around the samples in both cases.

\subsection{Resistance of Surface Concrete}

From the results of surface resistivity testing, it is evident that the results shown in Fig. 11 do not show a significant difference between curing regimes. This was not unexpected, as the region of influence with respect to salt scaling is in the uppermost region of the slab. Thus, the similarity in the results would be indicative of portions deeper in the slab that have not been significantly influenced by the curing method and would be expected to be similar as the concrete was from the same batch. Any differences in the resistance reading are more likely due to the variability of the moisture content at the surface. It should be noted that measurements are recommended to be taken on a saturated surface dry condition which was not the case in this study. This is why all the measured resistance values are high.

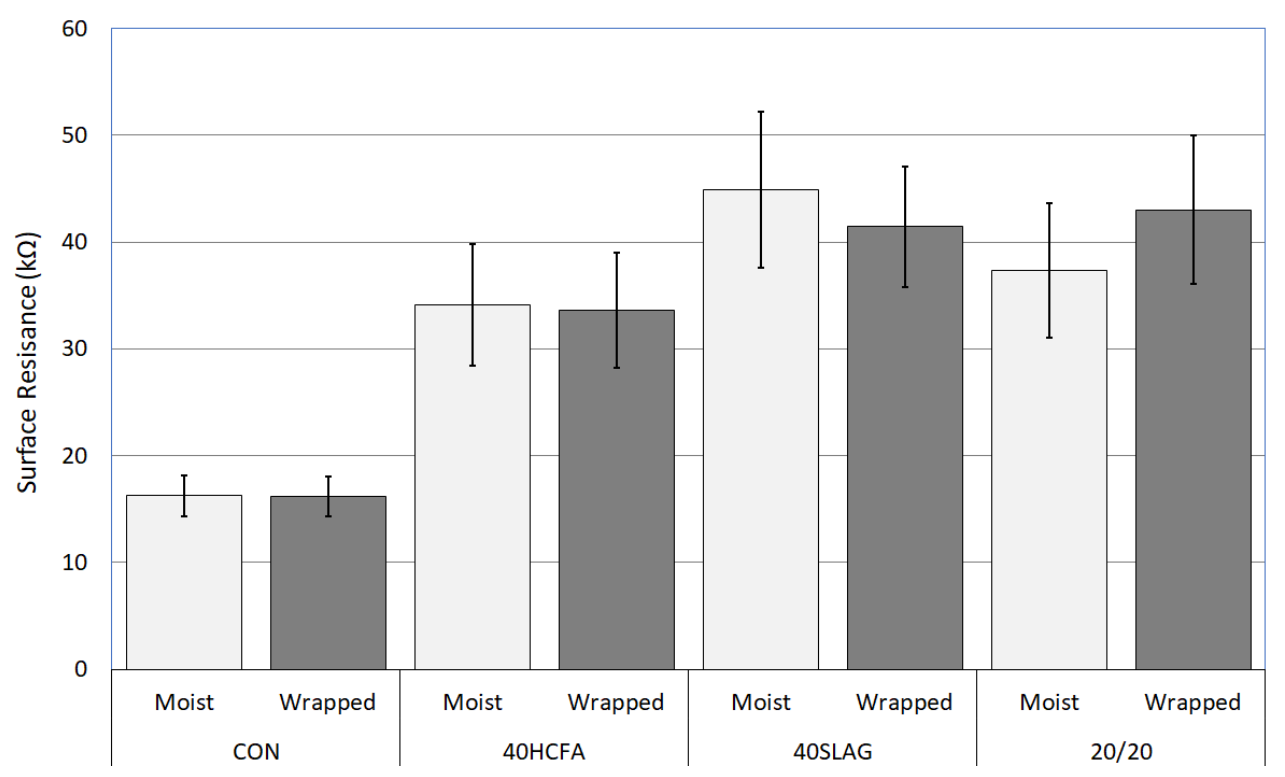

Fig. 11. Surface resistance of concrete slab samples 


\section{Discussion}

The primary intention of this paper was to study the effects of the curing method on salt scaling resistance of concrete with SCM. The wrapping method investigated here is to represent a method of curing that does not involve introducing additional water to the concrete, such as the perfect application of curing compound. The application of curing compound was not investigated in this lab investigation, as the process of removing the curing compound prior to exposing the slabs to the salt solution is likely to affect the surface of the concrete. While moist curing allowed for an excess of moisture to be continually available during the curing period, the wrapped method, on the other hand, provided only the moisture available from the original water present in the concrete. Humidity probes placed inside the wrapping show virtually $100 \%$ RH surrounding the slabs.

The control mix (CON) showed excellent resistance to scaling for all curing regimes and remained well below the MTO LS-412 failure limit of $0.8 \mathrm{~kg} / \mathrm{m}^{2}$ after $50 \mathrm{~F}-\mathrm{T}$ cycles (MTO, 1997). On the other hand, all samples with SCM performed poorly and failed before 30 F-T cycles. Comparison of moist and wrapped curing revealed the only samples that showed any measurable improvement in scaling resistance in the wrapped curing condition was the 40HCFA mix; with scaling damage of $1.42 \mathrm{~kg} / \mathrm{m}^{2}$ and $1.98 \mathrm{~kg} / \mathrm{m}^{2}$ for wrapped and moist samples, respectively. For samples containing 40\% HCFA (40HCFA), this improvement could be the result of a greater pozzolanic reactivity when wrapped due to less alkali leaching from the surface as was shown through the results of the alkali cations content in the surface concrete. The loss of alkalis from the surface is thought to be a result of water curing. The alkali content in the surface of the 40HCFA slabs was significantly higher in the wrapped specimens. The increased alkalinity could have promoted the pozzolanic activity of the fly ash leading to a higher degree of hydration in the surface concrete. 
As far as the curing methods are concerned, the differences in the scaling damage were relatively close to one another except for the sample with $40 \%$ HCFA where curing with water reduced scaling resistance. However, the curing method did not change the final outcome of the test in terms of passing or failing; samples with SCM cured with both curing methods failed the test. It should be noted that the water-to-cementing materials ratio $(\mathrm{w} / \mathrm{cm})$ of this sample was 0.43 , which is slightly lower than the w/cm of the other samples (0.45). However, both curing methods - wrapped and moist curing - were applied to the same $40 \%$ HCFA mixture of w/cm of 0.43 . Boyd and Hooton (2007) showed that curing compound in field applications on concretes with up to $50 \%$ slag performed better than water curing methods but did not comment as to the reasons why this was the case. Similarly, Afrani and Rogers (1993) showed curing compound in outdoor exposure performed better than curing compound in lab conditions for concrete containing $25 \%$ slag. In this investigation, wet curing produced slightly better scaling resistance than slag samples cured by wrapping, although the difference was not significant.

For fly ash concretes, it has been noted that improvements in scaling resistance in laboratory samples are evident when curing compound is used (Bilodeau et al., 1991; Bilodeau \& Malhotra, 1997). From the work of Boyd and Hooton (2007) it was evident that there was a clear improvement when curing compound was used in conjunction with normal finishing times (immediately after bleed water disappears) on field exposed samples with $15 \%$ fly ash replacement; although the level of damage was low in both samples. In their experiments, the curing compound was not deliberately removed before exposure to de-icing salts, however the specimens were exposed to heavy truck traffic loads, which is more indicative of realworld applications (Boyd \& Hooton, 2007). 
For the ternary blend with $20 \%$ HCFA and $20 \%$ slag (20/20), the average mass loss of the wrapped specimens did not prove to be substantially lower than the moist-cured specimens. This is contrary to Boyd and Hooton (2007), who showed a ternary blend of $25 \%$ slag and $10 \%$ fly ash cured with curing compound and finished with normal timing suffered only about $1 / 3$ of the damage compared to wet curing in the field. Again, from the experiments of Boyd and Hooton (2007) the curing compound was not removed deliberately but was exposed to heavy truck traffic before exposure to de-icing salts. The results presented in this paper suggest that the anticipated high alkali levels in the surface concrete with SCM cured using curing compound could be one of the reasons for its enhanced performance.

There was no trend found with respect to compressive strength and scaling damage. This was not unexpected as the scaling damage is largely controlled by the surface properties of the concrete, which can be different from the properties of the core of concrete (Gagne et al., 2011). Similarly, the results of the surface resistivity did not reveal any significant relationship with the surface properties of samples and scaling damage. This is likely due primarily to the limitations of the measuring apparatus to detect any differences in the uppermost region of the slab surface as most of the detected resistance is from deeper regions of the slab as explained by Ewins (1990). In addition, the test was run on samples that are not in a saturated surface dry condition which is not the recommendation for this test.

\section{Conclusions}

From the range of materials investigated in this paper and the followed procedures, the following conclusions were drawn:

1. There is no significant benefit, with respect to salt scaling resistance, from the use of wrapped curing over that of wet curing methods under lab conditions. 
2. Regardless of the adopted curing regime, mixes without SCM showed excellent resistance to salt scaling compared to samples with SCM when exposed to the salt solution and freezing/thawing cycles at the age of 28 days.

3. There is evidence that sealed curing of concrete samples with SCM may result in a greater degree of hydration of SCM that exhibit pozzolanic activity, such as fly ash, compared to wet curing. This produced higher resistance to scaling, although it did not make the samples pass the test. The w/cm of the sample with fly ash tested here was 0.43 compared to 0.45 in all other samples. However, both methods of curing were applied to the same fly ash mixture of w/cm of 0.43 .

4. The enhanced scaling resistance of samples containing fly ash cured by wrapping was linked to higher alkali content at the surface concrete. This is likely to be a result of the reduced alkali leaching in wrapped samples promoting the pozzolanic activity of the SCM, HCFA in this paper.

5. Mix containing $40 \%$ slag showed similarly poor salt scaling resistance regardless of curing condition, with the moist specimen showing only slightly better scaling resistance. This is due to the weaker surface of samples with such volume of SCM when tested at the age adopted here.

\section{Data Availability}

All data, models, and code generated or used during the study appear in the submitted article.

\section{Acknowledgments}

Funding for this research is supported by a Discovery Grant from the Natural Sciences and Engineering Research Council of Canada. The financial support of this organization is highly appreciated. 


\section{References}

Afrani, I., and Rogers, C. A. (1993). "The effect of different cementing materials and curing regimes on the scaling resistance of concrete." (Vol. MI-166.): Ontario Ministry of Transportation, Engineering Materials Office.

Ahani, R.M and Nokken, M.R. (2012) "Salt scaling resistance - The effect of curing and presaturation." Construction and Building Materials, 26, 558-564

ASTM (2012). "Standard Test Method for Electrical Indication of Concrete's Ability to Resist Chloride Ion Penetration.” ASTM C1202, Conshohocken, PA: ASTM International.

ASTM (2013). "Standard Test Method for Measurement of Rate of Absorption of Water by Hydraulic-Cement Concretes." ASTM C1585, West Conshohocken, PA: ASTM International.

ASTM (2014a). "Standard Test Method for Air Content of Freshly Mixed Concrete by the Pressure Method.” ASTM C231, Conshohocken, PA: ASTM International.

ASTM (2014b). "Standard Test Method for Bleeding of Concrete." ASTM C232, Conshohocken, PA: ASTM International.

ASTM (2015). "Standard Test Method for Slump of Hydraulic-Cement Concrete." ASTM C143, Conshohocken, PA: ASTM International.

ASTM (2016). "Standard specification for air-entraining admixtures for concrete." ASTM C260, Philadelphia, PA: ASTM.

ASTM (2016). "Standard specification for chemical admixtures for concrete." ASTM C494, Philadelphia, PA: ASTM.

ASTM (2003). "Standard test method for scaling resistance of concrete surfaces exposed to deicing chemicals." ASTM standard C672-03, American Society for Testing and Materials, 
West Conshohocken, Pa.

Bilodeau, A., \& Malhotra, V. M. (1997). "Deicing salt scaling resistance of concrete incorporating supplementary cementing materials: CANMET research.” Rilem proceedings 30. Freeze-thaw durability of concrete.

Bilodeau, A., Carette, G. G., \& Malhotra, V. M. (1991). "Influence of Curing and Drying on Salt Scaling Resistance of Fly Ash Concrete.” Special Publication, 126(126-11), 201-228. doi:10.14359/2126

Bilodeau, A., Zhang, M. H., Malhotra, V. M., \& Golden, D. M. (1998). "Effect of Curing Methods and Conditions on the Performance of Fly Ash Concrete in De-king Salt Scaling." Special Publication, 178. doi:10.14359/5988

BNQ. (2002). “Améliorer ses performances. Programmes de certification.” NQ 2621-900, Bureau de Normalisation du Québec, Montréal, Que.

Bouzoubaâ, N. Bilodeau, A. Fournier, B. Hooton, R.D. Gagné, R. and Jolin, M. (2011) “Deicing Salt Scaling Resistance of Concrete Incorporating Fly Ash and/or Silica Fume: Laboratory and Field Sidewalk Test Data." Canadian Journal of Civil Engineering, 38, 373-382.

Boyd, A. J., \& Hooton, R. D. (2007). "Long-Term Scaling Performance of Concretes Containing Supplementary Cementing Materials." Journal of Materials in Civil Engineering, 19(10), 820-825. doi:10.1061/(ASCE)0899-1561(2007)19:10(820)

Chidiac, S. E., \& Panesar, D. K. (2008). "Evolution of mechanical properties of concrete containing ground granulated blast furnace slag and effects on the scaling resistance test at 28 days." Cement and Concrete Composites, 30(2), 63-71.

CSA (2014). "Concrete materials and methods of concrete construction/Test methods and standard practices for concrete.” CSA A23.1-14/A23.2-14, Ontario, Canada: Canadian 
Standard Association.

CSA (2019). "Concrete materials and methods of concrete construction/test methods and standard practices for concrete." CSA Standard A23.2:19 - 22C, Canadian Standards Association, Mississauga, Ont.

CSA (2019). "Concrete materials and methods of concrete construction/test methods and standard practices for concrete." CSA Standard A23.2:19 - 9C, Canadian Standards Association, Mississauga, Ont.

Ewins, A. J. (1990). "Resistivity Measurements in Concrete." British Journal of NonDestructive Testing, 32(3), 120-126. Cited in: Chini, Muszynski, \& Hicks, 2003.

Gagne, R., Houehanou, E., Jolin, M., \& Escaffit, P. (2011). "Study of the relationship between scaling resistance and sorptivity of concrete." Canadian Journal of Civil Engineering, 38(11), 1238-1248. doi:10.1139/111-084

Galan, I., Andrade, C., \& Castellote, M. (2013). "Natural and accelerated CO2 binding kinetics in cement paste at different relative humidities." Cement and Concrete Research, 49, 21-28. doi:http://dx.doi.org/10.1016/j.cemconres.2013.03.009

Lawler, J. S. (2007). "Guidelines for concrete mixtures containing supplementary cementitious materials to enhance durability of bridge decks." Report No. 588.

Marchand, J., Maltais, Y., \& Machabee, Y. (2004). "Effects of fly ash on microstructure and deicer salt scaling resistance of concrete.” Frost Resistance of Concrete, 34, 12.

Mehta, P. K., \& Monteiro, P. J. M. (2006). “Concrete: microstructure, properties, and materials" (Vol. 3rd): McGraw-Hill.

MTO. (1997). "Method of test for scaling resistance of concrete surfaces exposed to de-icing chemicals.” MTO LS-412 Rev. No. 17 (pp. 5): Ministry of Transportation of Ontario.

Neville, A. M. (2011). “Properties of concrete (5th ed.).” Pearson. 
Ngala, V. T., \& Page, C. L. (1997). "Effect of Carbonation on Pore Structure and Diffusional Properties of Hydrated Cement Pastes." Cement and Concrete Research, 27(7), 995-1007. doi:10.1016/S0008-8846(97)00102-6

OPSS. (2013). “Material Specification for Aggregates-Concrete.” OPSS.PROV 1002. Ontario, Canada: Ontario Provincial Standard Specification.

Papadakis, Vagelis G. (2000). "Effect of Supplementary Cementing Materials on Concrete Resistance against Carbonation and Chloride Ingress." Cement and Concrete Research, 30(2), 291-299., doi:10.1016/S0008-8846(99)00249-5.

Pigeon, M., Talbot, C., Marchand, J., \& Hornain, H. (1996). "Surface microstructure and scaling resistance of concrete." Cement and Concrete Research, 26(10), 1555-1566. doi:10.1016/0008-8846(96)00138-X

Popovics, S. (1992). “Concrete materials: properties, specifications and testing.” (Second ed.): Noyes Publications.

Shehata, M. H. (2001). "The effects of fly ash and silica fume on alkali-silica reaction in concrete.” (Ph.D.), University of Toronto

Shehata, M. H., Thomas, M. D. A., \& Bleszynski, R. F. (1999). "The effects of fly ash composition on the chemistry of pore solution in hydrated cement pastes." Cement and Concrete Research, 29(12), 1915-1920. doi:10.1016/S0008-8846(99)00190-8

Siddiqui, M. S., Nyberg, W., Smith, W., Blackwell, B., \& Riding, K. A. (2013). "Effect of Curing Water Availability and Composition on Cement Hydration." ACI Materials Journal, 110(3), 315-322.

Stark, J., \& Ludwig, H. M. (1997). "Freeze-deicing salt resistance of concrete containing blast furnace slag cement.” Freeze-thaw durability of concrete, 107-120.

Talbot, C., Pigeon, M., \& Marchand, J. (2000). "Influence of Fly Ash and Slag on Deicer Salt 
Scaling Resistance of Concrete.” Special Publication, 192. doi:10.14359/5776

Thomas, M. D. A. (2013). "Supplementary cementing materials in concrete.” Boca Raton, FL: CRC Press.

Valenza II, J. J., \& Scherer, G. W. (2006). "Mechanism for Salt Scaling." Journal of the American Ceramic Society, 89(4), 1161-1179. doi:10.1111/j.1551-2916.2006.00913.x

Valenza II, J. J., \& Scherer, G. W. (2007a). "A review of salt scaling: I. Phenomenology." Cement and Concrete Research, 37(7), 1007-1021. doi:10.1016/j.cemconres.2007.03.005

Valenza II, J. J., \& Scherer, G. W. (2007b). “A review of salt scaling: II.” Mechanisms. Cement and Concrete Research, 37(7), 1022-1034. doi:10.1016/j.cemconres.2007.03.003 